\title{
Novel strategies in the use of lopinavir/ritonavir for the treatment of HIV infection in children
}

\author{
This article was published in the following Dove Press journal: \\ HIVIAIDS - Research and Palliative Care \\ 27 March 2010 \\ Number of times this article has been viewed
}

\author{
Beatriz Larru Martinez' \\ F Andrew I Riordan ${ }^{2}$ \\ 'Laboratorio Inmuno-Biología \\ Molecular, Hospital General \\ Universitario Gregorio Marañón, \\ Madrid, Spain; ${ }^{2}$ Department of \\ Infectious Diseases, Alder Hey \\ Children's NHS Foundation Trust, \\ Liverpool, UK
}

\begin{abstract}
Lopinavir/ritonavir (LPV/r) is considered by many as the first choice protease inhibitor (PI) for children. This co-formulation avoids the need for children to take ritonavir separately to "boost" the levels of lopinavir. LPV/r has high virologic potency, an excellent toxicity profile and a high barrier to the development of viral resistance. However, LPV/r has poor tolerability of the oral suspension (due to the poor taste of ritonavir), difficult dosing requirements and metabolic side effects, especially hyperlipidemia. The new tablet low-dose formulation $(100 / 25 \mathrm{mg}$ ) may allow more convenient antiretroviral treatment in children. Novel strategies of LPV/r in childhood could maximize its advantages. For example, infants infected with HIV despite single dose Nevirapine after birth need effective combination antiretroviral treatment. This can be given using a higher dose of LPV/r with therapeutic drug monitoring. Other novel uses include once daily LPV/r regimens in older children and adolescents and lower doses of LPV/r in certain populations, which may decrease hyperlipidemia. Heavily pre-treated children might benefit from a double PI/r regimen which includes LPV/r. The high potency of LPV/r needs to be balanced with convenient regimens, to enhance adherence and decrease toxicity whenever possible. The aim of this review is to discuss the rationale behind these novel strategies of LPV/r use in pediatric antiretroviral treatment as well as their results and limitations.
\end{abstract}

Keywords: human immunodeficiency virus, children, antiretroviral therapy, lopinavir, ritonavir

\section{Introduction}

Since the emergence of the HIV/AIDS pandemic children worldwide have suffered its devastating consequences. In 2007, UNAIDS estimated that 2.1 million children under 15 years old were living with HIV/AIDS, 420,000 children acquired the infection and 290,000 died of AIDS during this year. ${ }^{1,2}$

Without treatment, many HIV-infected children will die during the first year of life and half will not survive to their tenth birthday. Combination treatment (with 3 or more antiretroviral drugs) has dramatically changed the outlook for children with HIV infection, producing a marked decrease in mortality. ${ }^{3}$ This outstanding outcome has been particularly noticeable since the introduction of the protease inhibitors (PI) as part of Highly Active Antiretroviral Therapy (HAART) in 1997.4-6

The PIs are a class of antiretroviral drug that bind competitively to the viral protease enzyme that inhibits the cleavage of the gag-pol polyprotein. This results in production of immature non-infectious viral particles, and prevents subsequent cellular infection. Currently, 9 PIs are approved for the treatment of HIV-infection, 7 of which are approved
Correspondence: A Riordan Haematology Treatment Centre, Alder Hey Children's NHS Foundation Trust, Eaton Road, Liverpool, LI2 2AP, UK Fax +44 (0) I5I 2525929

Email andrew.riordan@alderhey.nhs.uk 
for use in children and have pediatric drug formulations. Most PIs are "boosted" by low-dose ritonavir (an extremely potent inhibitor of cytochrome P450 3A4 activity), which prevents metabolism of the second PI, leading to high levels. Boosted atazanavir, fosamprenavir, darunavir and saquinavir have comparable efficacy with boosted lopinavir in adults, but there are few pediatric data. ${ }^{9,10}$

There is much variability among pediatricians about what HAART to prescribe for children. Current recommendations suggest combinations of two nucleoside reverse transcriptase inhibitors (NRTIs) plus either a non-nucleoside reverse transcriptase inhibitor (NNRTI) or a PI. ${ }^{9}$ The choice of whether to use a PI or an NNRTI in children is still unclear and is being addressed in the PENPACT 1 study (a 4-year randomized trial which finished in 2009). ${ }^{7,8}$

If a PI-based regimen is selected in children, lopinavir/ ritonavir (LPV/r) is the preferred PI as most pediatric data are available for this PI. Numerous adult and pediatric studies have shown a high virologic potency, an excellent toxicity profile and a high barrier to develop resistance. ${ }^{9}$ However, LPV/r has several limitations, such as poor tolerability of the oral suspension, difficult dosing requirements and undesirable metabolic side effects, especially hyperlipidemia which has unknown consequences as the child grows into adulthood. ${ }^{10-12}$

Children and infants provide unique challenges for antiretroviral treatment. Firstly, they have higher viral loads than adults, due to an immature immune system that is unable to control viral replication. Secondly, accurate drug dosing is problematic, particularly in small children for whom lack of pharmacokinetic data and pediatric formulations reduce the availability of effective antiretroviral therapy (ART) and may predispose to sub-therapeutic drug levels. Finally, the need for a caregiver to administer the drugs to a child makes it hard to achieve the required $>95 \%$ adherence throughout childhood. For all these reasons, data derived from adult studies are not entirely applicable to children and specific pediatric trials have to be conducted. ${ }^{4}$

In industrialized settings HIV infection is increasingly considered as a chronic disease. Multiple initiatives have aimed to simplify treatment and enhance adherence, as treatment may have to be lifelong. This is particularly relevant in pediatrics due to the longer course of the infection. Several studies have examined new therapeutic approaches such as monotherapy with high efficacy ART, low-dose combinations or dual PI regimens. LPV/r has been used in this way and the aim of this review is to discuss the rational behind these novel strategies of LPV/r use in pediatric antiretroviral treatment as well as their results and limitations.

\section{Lopinavir/ritonavir in pediatric antiretroviral treatment}

LPV/r was the sixth PI approved by the Food and Drug Administration (FDA). It is the only PI co-formulated as a fixed combination of lopinavir (LPV, initially known as ABT-378) and ritonavir (RTV). Ritonavir inhibits the hepatic metabolism of lopinavir increasing its plasma concentration. ${ }^{13}$ Ritonavir can be given separately to "boost" other PIs. However ritonavir suspension has an extremely poor taste and the capsule is large, making adherence in children extremely difficult. The co-formulation of RTV with LPV avoids some of these issues, although the suspension still has a poor taste.

$\mathrm{LPV} / \mathrm{r}$ soft-gelatine capsule and oral solution were the first formulations approved for use in children. In March 2006, the capsule was replaced with a tablet formulation that used proprietary melt-extrusion technology. This offers several advantages over the capsule formulation, such as, lower pill burden, fewer gastrointestinal adverse effects and easier storage requirement (no need for refrigeration). In November 2007, the FDA approved a low strength tablet formulation $(100 / 25 \mathrm{mg}$ ) for the use in children (available in the EU since 2008). ${ }^{14,15}$ The major disadvantage of the new tablet formulation is that the tablets can not be cut or crushed, as bioavailability is lost. This can make accurate dosing in children difficult. For example a child requiring $250 / 62.5 \mathrm{mg}$ of LPV/r twice daily may either be given $200 / 50 \mathrm{mg}$ in tablet form plus 50/12.5 $\mathrm{mg}$ as suspension twice daily, or $200 / 50 \mathrm{mg}$ in tablet form in the morning and $300 / 75 \mathrm{mg}$ in tablet form in the evening. Neither of these regimens is ideal and the pediatrician and caregivers will have to discuss which is most likely to achieve good adherence.

Currently several dosage forms of LPV/r are available for the treatment of pediatric HIV-infection (see Tables 1 and 2). A brief summary of the main pharmacokinetic and pharmacodynamic properties of LPV/r is shown in Table 3.

\section{New strategies on the use of LPV/r in pediatric antiretroviral treatment}

The limitations observed with the long-term use of LPV/r in children have impelled the scientific community to explore

Table I Dosage forms of LPV/ra

- Oral solution containing lopinavir $80 \mathrm{mg} / \mathrm{mL}$ and ritonavir $20 \mathrm{mg} / \mathrm{mL}$

- Film-coated tablets containing lopinavir $200 \mathrm{mg}$ and ritonavir $50 \mathrm{mg}$

- Film-coated tablets containing lopinavir $100 \mathrm{mg}$ and ritonavir $25 \mathrm{mg}$

aThe capsule was withdrawn in 2008. 
Table 2 Pediatric dosing scheme for LPV/ $\mathrm{r}^{39,48}$

\begin{tabular}{ll}
\hline Children aged I4 days to 6 months & $\begin{array}{l}16 / 4 \mathrm{mg} / \mathrm{kg} \text { or } 300 / 75 \mathrm{mg} / \mathrm{m}^{2} \\
\text { twice daily }\end{array}$ \\
$\begin{array}{ll}\text { Children aged } 6 \text { months to } 12 \text { years } \\
\text { - Weight: } 7 \text { to } 15 \mathrm{~kg}\end{array}$ & $\begin{array}{l}12 / 3 \mathrm{mg} / \mathrm{kg} \text { or } 230 / 57.5 \mathrm{mg} / \mathrm{m}^{2} \\
\text { twice daily }\end{array}$ \\
& $10 / 2.5 \mathrm{mg} / \mathrm{kg}$ or $230 / 57.5 \mathrm{mg} / \mathrm{m}^{2}$ \\
-Weight: 15 to $40 \mathrm{~kg}$ & $400 / 100 \mathrm{mg}$ twice daily)
\end{tabular}

Children aged 6 months to 18 years with co-administration of EFV, NVP, NFV or (fos)amprenavir in either naive or treatment-experienced patients

$$
\begin{array}{ll}
\text {-Weight: }<15 \mathrm{~kg} & \mid \mathrm{I} / 3.25 \mathrm{mg} / \mathrm{kg} \text { twice daily } \\
\text {-Weight: }>15 \mathrm{~kg} & \mathrm{I} / 2.75 \mathrm{mg} / \mathrm{kg} \text { twice daily with- } \\
& \text { out exceeding the adult dose }
\end{array}
$$

Abbreviations: LPV/r, lopinavir/ritonavir; EFV, efavirenz; NVP, nevirapine; NFV, nelfinavir.

new ways to benefit from the high antiviral potency of LPV/r minimizing its disadvantages.

\section{Use of LPV/r in infants}

The risk of disease progression in HIV is inversely correlated with the age of the child, with the youngest children at greatest risk of rapid progression. ${ }^{16,17}$ Currently, both European and American guidelines recommend that antiretroviral treatment should be started in every HIV infected infant under 12 months of age regardless of immune status or viral load. ${ }^{18}$ This recommendation follows a 4-fold reduction in HIV progression/mortality among infants starting HAART at less than 3 months of age compared to later, in both a large cohort meta-analysis and a randomized controlled trial. ${ }^{19,20}$

This is particularly relevant in resource-limited settings where most children with HIV/AIDS live. The mortality rate of HIV-infected children in developing countries is $45 \%$ to $59 \%$ by 2 years of age compared with $10 \%$ to $20 \%$ in the EU and the US but early ART among infants between 6 to 12 weeks with CD $4 \% \geq 25$ has been associated with a reduction in mortality of $76 \%$. $^{19,21,22}$

Babies may be infected with HIV despite attempts to prevent mother-to-child transmission. In resourcelimited settings these infants will often have been given the NNRTI nevirapine (NVP). Those infants who become infected despite nevirapine use have a high risk of NNRTI resistance, raising concerns about the efficacy of NNRTIbased regimens within the first year of life in NVP-exposed infants. The efficacy of highly active agents other than NVP to treat very young infants, such as PIs, needed to be assessed. ${ }^{23}$
Table 3 Pharmacology and pharmacokinetics of LPV/r $\mathrm{r}^{14,48,49}$

Absorption Absorption of $L P V / r$ liquid formulation is affected by the presence of food (the AUC and the $\mathrm{C}_{\text {max }}$ of LPV increased by $130 \%$ and $56 \%$ respectively when given with a high-fat meal compared with a fasting state). $\mathrm{LPV} / \mathrm{r}$ tablets may be taken with or without food as long as the tablets are swallowed whole, without being chewed, crushed or broken.

$C_{\text {max }}$ of LPV of $9.8 \pm 3.7 \mu \mathrm{g} / \mathrm{mL} 4$ hours after the intake of the drug have been reported in adults after multiple dosing with $400 / 100 \mathrm{mg}$ twice daily during 3-4 weeks.

Minimum concentration within a dosing interval ( $12 \mathrm{~h})$ was $5.5 \pm 2.7 \mu \mathrm{g} / \mathrm{mL}$ Minimum effective concentration in treatment naïve adults has been established at $>I \mu \mathrm{g} / \mathrm{mL}$.

AUC during a 12 hour dosing interval was $92.6 \pm$ $36.7 \mu \mathrm{g}^{*} \mathrm{~h} / \mathrm{mL}$.

The absolute bioavailability of LPV/r has not been established in humans.

Distribution

LPV is approximately $98 \%-99 \%$ bound to plasma proteins (alpha-I-acid glycoprotein and albumin transport LPV).

$\mathrm{LPV} / \mathrm{r}$ accumulates intracellularly. Intracellular/plasma concentration of 1.18 has been reported.

LPV is lipid soluble therefore penetrates the cerebrospinal fluid where a significant reduction of HIV viral load has been shown.

Metabolism LPV is extensively metabolized by the hepatic cytochrome P450 system, almost exclusively by the CYP34 and CY3A5 isoenzymes.

RTV is a potent CYP34 inhibitor and consequently increases plasma levels of LPV when the two drugs are co-administered.

RTV has been shown to induce metabolic enzymes, resulting in the induction of its own metabolism.

Elimination

After administration of LPV/r, approximately $10.4 \% \pm$ $2.3 \%$ and $82.6 \% \pm 2.5 \%$ of the administered dose can be found in urine and feces respectively after 8 days. Unchanged LPV accounted for nearly 2.2 and $19.8 \%$ of the administered dose in urine and feces, respectively. The apparent oral clearance of LPV is $5.98 \pm 5.75 \mathrm{~L} / \mathrm{h}$.

Abbreviations: $L P V / r$, lopinavir/ritonavir; $A \cup C$, area under the curve; $C_{\max }$, maximum plasma concentration; LPV, lopinavir; RTV, ritonavir.

$\mathrm{LPV} / \mathrm{r}$ could thus be considered as one of the first-line agent choices for early antiretroviral treatment because of its liquid formulation. ${ }^{24}$

Nelfinavir was the first PI used extensively in children. High doses were needed to achieve effective drug levels in infants and there was great intersubject variation. Poor longterm viral suppression was reported with nelfinavir given in the first 3 months of life (11 out of 16 infants experienced virological failure and $30 \%$ developed resistance). ${ }^{25}$

$\mathrm{LPV} / \mathrm{r}$ was initially approved in Europe for children older than 2 years and it has become the first choice PI in children. ${ }^{26}$ However young infants have a higher apparent clearance 
of drugs and altered absorption. Extrapolating the dosage schedule followed in older children could lead to potential toxicity and/or lower exposure in young infants to ART, with incomplete virological suppression and the subsequent risk of viral resistance. ${ }^{27}$

The different absorption and distribution of LPV/r in young children compared with older children was initially observed by Verweel et al in a retrospective cohort study of 23 children who underwent a 12-hour pharmacokinetic sampling for LPV. Children under 2 years of age had a significantly lower $\mathrm{C}_{\min }$ and $\mathrm{C}_{\max }$ compared to children older than 2 years of age after receiving LPV/r 230/57.5 mg/m² twice daily. A dose increase by $37 \%$ resulted in an adequate LPV trough concentration in children younger than 2 years. Therefore a higher dose of $300 / 75 \mathrm{mg} / \mathrm{m}^{2}$ twice a day in children less than 2 years old was suggested. ${ }^{28}$ Chadwick et al investigated the pharmacokinetics, safety and efficacy of LPV/r plus two NRTIs in infants aged between 6 weeks and 6 months in a prospective trial including 21 infants. Infants received LPV/r 300/75 mg/m² twice daily and were followed for 24 weeks. LPV/r clearance was slightly higher than that observed in older children, but the median AUC-time curve 0-12 $\mathrm{h}$ was similar to that seen in older children receiving $230 / 57.5 \mathrm{mg} / \mathrm{m}^{2}$ of LPV/r. The trough levels stabilized after the first 2 weeks of the study, which according to the authors, could be explained by improved absorption of the drug, better technique of administration, dietary changes or variation in RTV oral clearance. ${ }^{24}$

A median decrease in HIV viral load (VL) of 3.13 $\log 10$ copies/mLwas observed at week 24 , but only $38 \%$ had an undetectable VL $(<400$ copies/mL) at weeks 16 and 24 . The virological response at week 16 was not associated with the LPV/r exposure at week 2, but viral suppression improved over time during the study. One infant interrupted treatment within the first 2 weeks of the study because of vomiting. $14.3 \%$ of the infants experienced a grade 3 or higher adverse events (transient neutropenia) but all were asymptomatic and transient. The authors concluded that a twice-daily dose of $300 / 75 \mathrm{mg} / \mathrm{m}^{2}$ of LPV/r in infants under 6 months gave a similar exposure to that reported in older children with favorable clinical and virological efficacy. ${ }^{24}$

Chadwick and colleagues also reported the use of LPV/ r-based regimens in infants less than 6 weeks of age in a prospective, phase I/II study. This included 10 infants with confirmed HIV-1 infection aged between 2 and 6 weeks who received $300 / 75 \mathrm{mg} / \mathrm{m}^{2}$ of LPV/r twice daily plus 2 NRTIs and were followed 24 weeks. The median LPV AUC of $36.6 \mu \mathrm{g} / \mathrm{mL}$ was significantly lower than that found in infants aged between 6 weeks and 6 months of age. The half-life of LPV was similar to that seen in older infants, so the authors postulated that reduced bioavailability of LPV could be the main cause for the lower LPV exposure rather than enhanced LPV metabolism. Altered absorption of LPV/r could be due to the food intake of the infants enrolled, though there was no correlation between the time and volume of formula milk received and LPV exposure in this study. The authors suggested that the addition of other foods might enhance LPV bioavailability in this age group. This needs to be evaluated in larger trials. This is particularly important because most infants that might benefit from early ART also suffer concomitant food insecurity. ${ }^{27}$

The authors assessed that despite the lower peak and average LPV exposure observed, the LPV trough was similar to that reported in older infants and an excellent virological response was achieved. The long-term follow-up of these patients would help to determine the variations of $\mathrm{LPV} / \mathrm{r}$ pharmacokinetics and its long-term efficacy. ${ }^{27}$

These initial studies suggest that LPV/r may be used in young infants, but if used therapeutic drug monitoring (TDM) should be always considered. Data from larger trials are needed to evaluate the impact that other factors (like genetics or race) might have on LPV/r exposure during the first months of life. An improvement in the palatability of the oral formulation of LPV/r is urgently needed if extensive use of this drug is recommended after the early diagnosis of the HIV infection. Otherwise, poor adherence with possible incomplete viral suppression and resistance might happen early in life and make future antiretroviral treatment even more complex.

\section{Monotherapy with LPV/r}

The dramatic success of HAART has also brought important complications such as lipodystrophy, dyslipidemia or lactic acidosis. Complex dosing schedules with a high daily pill burden hinders the benefits of HAART and compromises its long-term use. Therefore, strategies like monotherapy with highly potent ART such as a boosted PI (PI/r) seemed an appealing way to enhance adherence and decrease complications. Single-drug antiretroviral therapy may be less toxic, easier to use and less costly while effectively maintaining long-term virological suppression and preserving future treatment options. ${ }^{29}$

\section{Adult studies - LPV/r monotherapy after initial HAART}

The use of LPV/r monotherapy as an NRTI-sparing treatment simplification strategy in patients with sustained viral 
suppression was evaluated by Moltó et al in a retrospective cohort of 51 adults; $95 \%$ of the patients who were followed until 48 weeks maintained viral suppression, with a sustained increase in CD4\% cell counts and a significant decrease in triglyceride levels. The authors concluded that this treatment simplification approach was safe and effective in routine clinical practice, especially in those patients already receiving a $\mathrm{LPV} / \mathrm{r}$ based regimen. ${ }^{30}$

Similar results were obtained in the OK04 study group in a randomized, open label, non-inferiority clinical trial in 205 patients with suppressed viral replication on LPV/r plus 2 NRTI. Patients were randomized to continue HAART or $\mathrm{LPV} / \mathrm{r}$ monotherapy with the reintroduction of 2 NRTIs if virological rebound was observed. At week 48, the percentage of patients without therapeutic failure was $94 \%$ in the monotherapy arm versus $90 \%$ in the triple therapy group. The percentage of patients with HIV RNA $\leq 50$ copies $/ \mathrm{mL}$ at week 48 by intention-to-treat analysis was $85 \%$ in the monotherapy groups versus $90 \%$ in the HAART arm, without statistically significant differences. Episodes of low level viremia were more common in patients receiving LPV/r monotherapy although the long-term significance of these "blips" is unknown. This study showed that LPV/r monotherapy (with reintroduction of NRTIs if needed) was non-inferior to conventional HAART. ${ }^{31}$

\section{LPV/r monotherapy in ART-naïve adult patients}

The use of LPV/r as monotherapy as initial therapy in adult patients was evaluated in the MONARK study; ${ }^{32}$ an openlabel, randomized, 96-week clinical trial which compare the efficacy of LPV/r monotherapy $(n=83)$ with LPV/r plus ZDV and $3 \mathrm{TC}(\mathrm{n}=53)$ as an initial treatment in naive patients with $\mathrm{VL}<100,000$ copies/mL. LPV/r monotherapy showed lower rates of virological suppression; in an intent-to-treat analysis $64 \%$ of the patients in the monotherapy group showed $\mathrm{VL}<50$ copies/mL, whereas $75 \%$ of those on conventional HAART maintained viral suppression. In the on treatment analysis, there was a significant difference on the patients who achieved an undetectable VL in both groups $(80 \%$ in LPV/r monotherapy vs $95 \%$ in the HAART group). Three patients in the monotherapy arm without virological suppression acquired new resistance mutations with modest impact on LPV susceptibility. This study did not support the use of $\mathrm{LPV} / \mathrm{r}$ monotherapy in ART-naïve adult patients.

Recently Ghosn et al reported the 96-week follow-up of the MONARK study. ${ }^{33}$ By an intention-to-treat analysis, $47 \%$ of those initially randomized to LPV/r monotherapy had sustained viral suppression $(<50$ copies $/ \mathrm{mL})$. The occurrence of low-level viremia in some patients during follow-up, with the subsequent risk of drug resistance, has discouraged the use of LPV/r monotherapy in ART-naïve HIV-infected adults.

\section{Pediatric studies}

Antiretroviral treatment in children achieves less viral suppression than in adults. Therefore, the use of LPV/r monotherapy in naïve children has been avoided and the potential role of LPV/r monotherapy in ART-experienced children with viral suppression evaluated with caution. A prospective clinical trial of the use of LPV/r monotherapy as maintenance in Thai children (aged between 2 and 28 years) after VL suppression is ongoing (HIV Netherlands Australia Thailand Research Collaboration). Results will not be available for some time. A Paediatric European Network for the Treatment of AIDS (PENTA) trial of LPV/r monotherapy after HAART is also planned. Meanwhile, based on the current evidence in adults, LPV/r monotherapy should be discouraged in children, particularly during the first years of life.

\section{LPV/r once-daily regimens}

Once-daily administration regimens could increase convenience and adherence as LePrevost et al showed with abacavir (ABC) plus 3TC use in children. ${ }^{34}$ However, the efficacy of once-daily ART is highly dependent on the maintenance of inhibitory concentrations throughout the entire dosing interval. $^{35}$

\section{Adult studies}

In treatment-naïve adults the administration of LPV/r in a single daily dose showed similar immunological and virological outcomes to the standard twice-daily regimen. Based on this experience, several studies have evaluated this new strategy with other drugs such as SQV/r in adult HIV-infected patients. ${ }^{36,37}$

\section{Pediatric studies}

In children, the change to a once-daily combination including boosted atazanavir in extensively ART experiencedchildren was associated with a significant risk of virological failure. Limited data are available about the use of other PIs, such as LPV/r, in a once-daily regimen. Pilot studies of once-daily LPV/r in children (dosed at 460/115 mg/m²) found similar pharmacokinetics to adult studies. However there was marked variation between individuals and studies; the observed median $\mathrm{C}_{\min }$ were just above the 
minimal effective concentration and around $50 \%$ of patients showed trough levels below inhibitory levels. The new tablet formulation gave better drug levels and less variation (see Table 4). ${ }^{38}$

The use of LPV/r once daily is still not recommended in pediatric antiretroviral treatment guidelines because there is no evidence yet from large trials. ${ }^{39}$ A PENTA trial is planned to study this in more detail (PENTA 18). ${ }^{40}$ All the pediatric trials of once-daily LPV/r have not included children under 2 years old who have a more erratic LPV/r exposure. If $\mathrm{LPV} / \mathrm{r}$ once daily is used in older children TDM should be carried out. Nevertheless, the advent of the tablet formulation of LPV/r, particularly the low-dose tablet, increases the feasibility of LPV/r once-daily regimens in children.

\section{Double boosted $\mathrm{PI}$ regimens}

When planning salvage regimens for children failing on NRTI/NNRTI-based HAART; pediatricians are often faced with multiple resistance mutations and limited options. Furthermore, response to salvage treatment containing a single PI might be suboptimal if little efficacy remains in the NRTI component or if progressive toxicity is associated with continued used of NRTIs. ${ }^{41}$

Dual ritonavir-boosted PI (PI/r) regimens represent an option for salvage or maintenance therapy for patients with reverse transcriptase mutations or intolerance. ${ }^{42}$ Double PI/r have the advantage of the boosting effect of RTV on plasma levels of both PIs and in vitro data have shown a synergistic effect of saquinavir (SQV) when combined with LPV/r. ${ }^{43}$

The efficacy of dual boosted PI combination has been assed in few studies among children. The combination of $\mathrm{LPV} / \mathrm{r}$ and saquinavir gave good virological responses, but was associated with increases in cholesterol. This combination is used in Thailand as an alternative for second line treatment in PI-naïve children who failed NRTIs/NNRTIs regimens, but the high pill burden makes adherence difficult (see Table 5).

Double boosted $\mathrm{PI} / \mathrm{r}$ regimens should not be used alone in naïve patients with high viral loads because they have been shown insufficient to suppress viral replication. Landman et al reported 61 naïve $\mathrm{HIV}$-infected adults who received fosamprenavir/atazanavir/RTV or saquinavir/atazanavir/ RTV; viral suppression was only achieved in $40 \%$ and $42 \%$ of patients respectively at week $16 .{ }^{44}$

However, the encouraging results in pre-treated children suggest that double $\mathrm{PI} / \mathrm{r}$ regimens may be an effective and safe option for these children. However, they also carry a high pill burden, and thus adherence support is extremely important. The additional benefit that TDM could add to this strategy needs to be studied in more detail in children, because a dose reduction could reduce the frequency of metabolic side effects without compromising its efficacy. The new low-dose tablet formulation of LPV/r allows the possibility of double $\mathrm{PI} / \mathrm{r}$ regimen with less toxicity and better acceptability.

Table 4 Summary of the pediatric studies on LPV/r once-daily regimens

\begin{tabular}{|c|c|c|}
\hline Author & Methods & Results \\
\hline Rosso et $\mathrm{al}^{50}$ & $\begin{array}{l}\text { 2I HIV-infected ART-naïve children } \\
\text { Dose of LPV/r } 460 / \text { I I } 5 \mathrm{mg} / \mathrm{m}^{2} \text { once daily as } \\
\text { soft-gel capsules after I month of } \\
\text { standard twice-daily therapy }\end{array}$ & $\begin{array}{l}\text { Median } C_{\min } 1.59 \mathrm{mg} / \mathrm{L} \text { in the once daily group vs } 7.90 \mathrm{mg} / \mathrm{L} \text { in the twice daily group. } \\
C_{\min } \text { inhibitory for wild-type virus }(>1.0 \mathrm{mg} / \mathrm{L}) \text { in } 4 \text { out of } 7 \text { children in the once } \\
\text { daily group } \\
\text { No significant differences in the } C_{\max } \text { between groups }\end{array}$ \\
\hline van der Lee et $\mathrm{a}^{51}$ & $\begin{array}{l}\text { 19 HIV-I infected ART-experienced children } \\
\text { with VL }<50 \text { copies } / \mathrm{mL} \text { for at least } 6 \text { months } \\
\text { Dose of LPV/r } 460 / I I 5 \mathrm{mg} / \mathrm{m}^{2} \text { once daily as } \\
\text { soft-gel capsules }\end{array}$ & $\begin{array}{l}\text { Median } C_{\min } 2.88 \pm 3.74 \mathrm{mg} / \mathrm{L} \text {, median } C_{\max } 10.77 \pm 2.90 \mathrm{mg} / \mathrm{L} \text {, } \\
\text { median } A \mathrm{CC}_{0-24} 149.8 \pm 58.8 \mathrm{~h} * \mathrm{mg} / \mathrm{L}-\text { comparable to adults receiving } \\
800 / 200 \mathrm{mg} \text { of LPV/r once daily. } \\
\mathrm{C}_{\min } \text { inhibitory for wild-type virus }(>1.0 \mathrm{mg} / \mathrm{L}) \text { in } 47 \% \text { children, less in } \\
\text { younger children }\end{array}$ \\
\hline la Porte et $\mathrm{al}^{52}$ & $\begin{array}{l}7 \text { pretreated children aged } 5 \text { to } 15 \text { years. } \\
\text { Dose of } \mathrm{LPV} / \mathrm{r} 460 / \mathrm{II} 5 \mathrm{mg} / \mathrm{m}^{2} \text { once daily or } \\
230 / 57.5 \mathrm{mg} / \mathrm{m}^{2} \text { twice daily as soft-gel capsules }\end{array}$ & 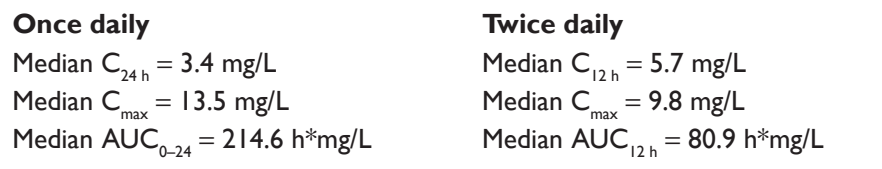 \\
\hline van der Flier et $\mathrm{al}^{53}$ & $\begin{array}{l}\text { I5 HIV-I infected children who had received } \\
\text { at least } 24 \text { weeks of LPV/r treatment (with } \\
\text { soft gel capsules) and had achieved virological } \\
\text { suppression. } \\
\text { Dose of LPV/r } 460 / I 15 \mathrm{mg} / \mathrm{m}^{2} \\
\text { once daily as tablet formulation }\end{array}$ & $\begin{array}{l}\text { Mean } C_{\min } 3.1 \pm 2.6 \mathrm{mg} / \mathrm{mL} \text {, mean } C_{\max } 14.8 \pm 2.4 \mathrm{mg} / \mathrm{L} \text {, } \\
\text { mean } A \cup C_{0-24} 217.9 \pm 44.9 \mathrm{mg} / \mathrm{L} * \mathrm{~h} \\
\text { LPV half-life }=5.8 \pm 4.5 \mathrm{~h} \text {; median time to maximum concentration }=5.8 \mathrm{~h} \text {. } \\
\text { Every child included in the study had an undetectable } V L \text { at week } 24 \text { of } \\
\text { follow-up }\end{array}$ \\
\hline
\end{tabular}

Abbreviations: $\mathrm{LPV} / \mathrm{r}$, lopinavir/ritonavir; $\mathrm{C}_{\text {min }}$, minimum plasma concentration; $\mathrm{C}_{\max }$, maximum plasma concentration; $\mathrm{PK}$, pharmacokinetic; $\mathrm{AUC}_{0-24}, 24 \mathrm{~h}$ area under the plasma concentration-time curve; $\mathrm{AUC}_{12 \mathrm{~h}}, 12 \mathrm{~h}$ area under the plasma concentration-time curve. 
Table 5 Summary of pediatric studies on double boosted PI regimens

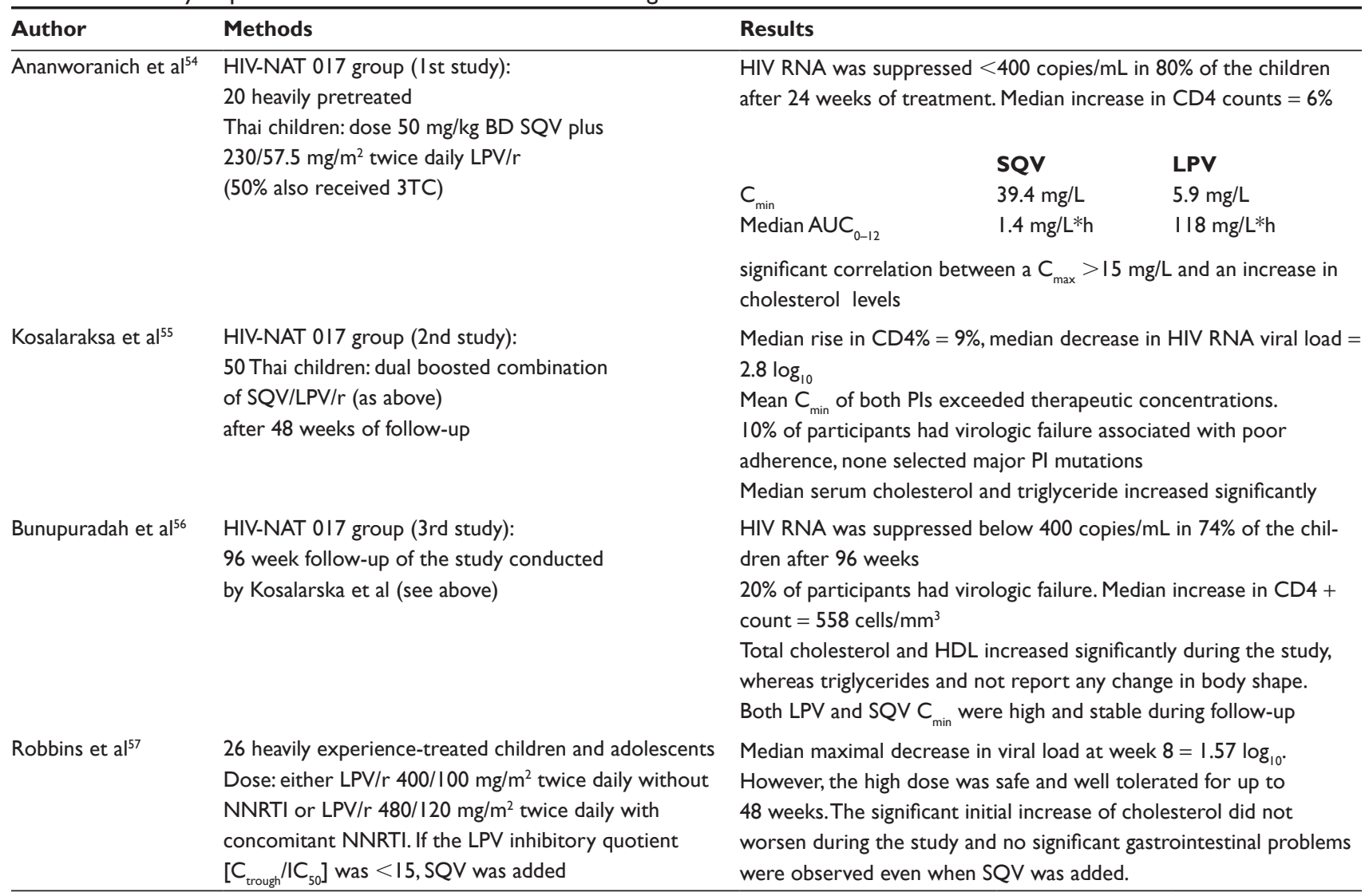

Abbreviations: $\mathrm{LPV} / \mathrm{r}$, lopinavir/ritonavir; $\mathrm{SQV}$, saquinavir; $\mathrm{AUC}_{0-12}, 12 \mathrm{~h}$ area under the plasma concentration-time curve; $\mathrm{C}_{\text {min }}$, minimum plasma concentration; $\mathrm{C}_{\text {max }}$, maximum plasma concentration; NRTIs/NNRTIs, nucleoside reverse transcriptase inhibitor/non-nucleoside reverse transcriptase inhibitor; PI, protease inhibitor.

\section{Low-dose LPV/r}

The effect that different isoenzyme polymorphisms have on the pharmacokinetics of drugs such as efavirenz has raised the importance of genetic factors in determining the dosage of ART. ${ }^{45}$ Studies have looked at using LPV/r at reduced doses in certain ethnic groups.

\section{Adult studies}

Boyd et al showed a satisfactory response and adequate PK profile in Thai adults with a $50 \%$ reduction in the dose of indinavir/RTV. Lower doses of saquinavir/ritonavir (SQV/r) and $\mathrm{LPV} / \mathrm{r}$ were also evaluated and a $70 \%$ dose of $\mathrm{LPV} / \mathrm{r}$ is currently accepted for Thai adults. ${ }^{46}$

\section{Pediatric studies}

The desirable benefits of LPV/r lower doses such as cost reduction and decreased rates of metabolic side effects would be valuable in pediatric antiretroviral treatment. A pilot study of low-dose LPV/r conducted by Puthanakit et al included 24 ART-naïve HIV-infected Thai children aged between 2 and 18 years. Patients received $70 \%$ of the standard dose twice a day plus zidovudine (ZDV) and lamivudine (3TC). At week
48, there were no statistically significant differences in CD4\% or viral load between children receiving the standard dose and those in the low-dose arm. The $\mathrm{AUC}_{0-12}$ and the $\mathrm{C}_{\text {trough }}$ were lower in the low-dose arm (by $29 \%$ and $31 \%$ respectively). ${ }^{47}$

This pilot study included a small number of patients, and a LPV/r dose-reduction is not yet recommended for PIexperienced children or infants. However the relevance of pharmacogenetic aspects on dosage schedule is proven and the need to adapt guidelines to different settings warranted. This study also suggests that TDM should be considered in all children on LPV/r in order to find out if a lower dose could be used. The advent of the new low-dose LPV/r tablets encourages the development of reduced dose studies among children due to its improved palatability and easier storage requirements compared with the liquid formulation.

\section{Conclusions}

The benefits achieved with LPV/r-based therapies in HIVinfected children outweighs the metabolic adverse effects observed with its prolonged used. Therefore, until other PIs develop child friendly formulations, LPV/r will be considered the first choice for PI in childhood. The new tablet low-dose 
formulation increases the possibility for more convenient antiretroviral treatment in children.

Novel strategies of LPV/r use could maximize its advantages during childhood; in infants a higher dosage with close TDM is a safe and effective option, especially in those exposed to single-dose NVP. Older children and adolescents could benefit from a once-daily LPV/r regimen and certain populations could be treated with lower doses if TDM can be guaranteed. Finally heavily pre-treated children might benefit from a double PI/r regimen which includes LPV/r.

All the previous approaches emphasize the lessons learnt with antiretroviral treatment in the past; high potency therapies need to be balanced with convenient regimens, to enhance adherence. No drug is effective if it is not taken and this is particularly challenging in children where both the patient and the caregiver needs to adhere to treatment.

\section{Disclosures}

The authors declare no conflicts of interest.

\section{References}

1. Homsy J, Moore D, Barasa A, Were W, Likicho C, Waiswa B, et al. Breastfeeding, Mother-to-Child HIV Transmission, and Mortality Among Infants Born to HIV-Infected Women on Highly Active Antiretroviral Therapy in Rural Uganda. J Acquir Immune Defic Syndr. 2009. [Sep 30 Epub ahead of print].

2. Sutcliffe CG, van Dijk JH, Bolton C, Persaud D, Moss WJ. Effectiveness of antiretroviral therapy among HIV-infected children in sub-Saharan Africa. Lancet Infect Dis. 2008;8(8):477-489.

3. Prendergast A, Mphatswe W, Tudor-Williams G, Rakgotho M, Pillay V, Thobakgale C, et al. Early virological suppression with three-class antiretroviral therapy in HIV-infected African infants. AIDS. 2008;22(11): 1333-1343.

4. Prendergast A, Tudor-Williams G, Jeena P, Burchett S, Goulder P. International perspectives, progress, and future challenges of paediatric HIV infection. Lancet. 2007;370(9581):68-80.

5. Doerholt K, Duong T, Tookey P, Butler K, Lyall H, Sharland M, et al. Outcomes for human immunodeficiency virus-1-infected infants in the United kingdom and Republic of Ireland in the era of effective antiretroviral therapy. Pediatr Infect Dis J. 2006;25(5):420-426.

6. Harwell JI, Obaro SK. Antiretroviral therapy for children: substantial benefit but limited access. JAMA. 2006;296(3):330-331.

7. Vaclavikova J, Machala L, Stankova M, Linka M, Bruckova M, Vandasova J, et al. Response of HIV positive patients to the long-term salvage therapy by lopinavir/ritonavir. J Clin Virol. 2005;33(4):319-323.

8. The devastating effects of HIV/AIDS on children. Lancet. 2006;368(9534):424.

9. Ramos J. Boosted protease inhibitors as a therapeutic option in the treatment of HIV-infected children. HIV Med. 2009;10(9):536-547.

10. Sharland M, Blanche S, Castelli G, Ramos J, Gibb DM. PENTA guidelines for the use of antiretroviral therapy, 2004. HIV Med. 2004;5 Suppl 2:61-86.

11. Shafran SD, Mashinter LD, Roberts SE. The effect of low-dose ritonavir monotherapy on fasting serum lipid concentrations. HIV Med. 2005;6(6):421-425.

12. Rudin C, Burri M, Shen Y, Rode R, Nadal D. Long-term safety and effectiveness of ritonavir, nelfinavir, and lopinavir/ritonavir in antiretroviral-experienced HIV-infected children. Pediatr Infect Dis J. 2008;27(5):431-437.
13. Saez-Llorens X, Violari A, Deetz CO, Rode RA, Gomez P, Handelsman E, et al. Forty-eight-week evaluation of lopinavir/ritonavir, a new protease inhibitor, in human immunodeficiency virus-infected children. Pediatr Infect Dis J. 2003;22(3):216-224.

14. Chandwani A, Shuter J. Lopinavir/ritonavir in the treatment of HIV-1 infection: a review. Ther Clin Risk Manag. 2008;4(5):1023-1033.

15. Klein CE, Chiu YL, Awni W, Zhu T, Heuser RS, Doan T, et al. The tablet formulation of lopinavir/ritonavir provides similar bioavailability to the soft-gelatin capsule formulation with less pharmacokinetic variability and diminished food effect. J Acquir Immune Defic Syndr. 2007;44(4):401-410.

16. Newell ML, Patel D, Goetghebuer T, Thorne C. CD4 cell response to antiretroviral therapy in children with vertically acquired HIV infection: is it associated with age at initiation? J Infect Dis. 2006;193(7):954-962.

17. Verweel G, Saavedra-Lozano J, van Rossum AM, Ramilo O, de Groot R. Initiating highly active antiretroviral therapy in human immunodeficiency virus type 1-infected children in Europe and the United States: comparing clinical practice to guidelines and literature evidence. Pediatr Infect Dis J. 2006;25(11):987-994.

18. Riordan A, Bugembe T. Update on antiretroviral therapy. Arch Dis Child. 2009;94(1):70-74.

19. Violari A, Cotton MF, Gibb DM, Babiker AG, Steyn J, Madhi SA, et al. Early antiretroviral therapy and mortality among HIV-infected infants. N Engl J Med. 2008;359(21):2233-2244.

20. Goetghebuer TH, Le Chenadec E. Early versus deferred highly active antiretroviral therapy in HIV infected infants: a European Collaborative Cohort Study. 4th Dominique Dormont International Conference: Host-Pathogen Interactions in Chronic Infections; Paris, France, 13-15 December, 2007.

21. Obimbo EM, Mbori-Ngacha DA, Ochieng JO, Richardson BA, Otieno PA, Bosire R, et al. Predictors of early mortality in a cohort of human immunodeficiency virus type 1-infected African children. Pediatr Infect Dis J. 2004;23(6):536-543.

22. Gortmaker SL, Hughes M, Cervia J, Brady M, Johnson GM, Seage GR 3rd, et al. Effect of combination therapy including protease inhibitors on mortality among children and adolescents infected with HIV-1. N Engl J Med. 2001;345(21):1522-1528.

23. Lockman S, Shapiro RL, Smeaton LM, Wester C, Thior I, Stevens L, et al. Response to antiretroviral therapy after a single, peripartum dose of nevirapine. N Engl J Med. 2007;356(2):135-147.

24. Chadwick EG, Capparelli EV, Yogev R, Pinto JA, Robbins B, Rodman JH, et al. Pharmacokinetics, safety and efficacy of lopinavir/ ritonavir in infants less than 6 months of age: 24 week results. AIDS. 2008;22(2):249-255.

25. Hirt D, Urien S, Jullien V, Firtion G, Rey E, Pons G, et al. Age-related effects on nelfinavir and M8 pharmacokinetics: a population study with 182 children. Antimicrob Agents Chemother. 2006;50(3):910-916.

26. Kline MW, Rugina S, Ilie M, Matusa RF, Schweitzer AM, Calles NR, et al. Long-term follow-up of 414 HIV-infected Romanian children and adolescents receiving lopinavir/ritonavir-containing highly active antiretroviral therapy. Pediatrics. 2007;119(5):e1116-e1120.

27. Chadwick EG, Pinto J, Yogev R, Alvero CG, Hughes MD, Palumbo P, et al. Early initiation of lopinavir/ritonavir in infants less than 6 weeks of age: pharmacokinetics and 24-week safety and efficacy. Pediatr Infect Dis J. 2009;28(3):215-219.

28. Verweel G, Burger DM, Sheehan NL, Bergshoeff AS, Warris A, van der Knaap LC, et al. Plasma concentrations of the HIV-protease inhibitor lopinavir are suboptimal in children aged 2 years and below. Antivir Ther. 2007;12(4):453-458.

29. Delaugerre C, Flandre P, Chaix ML, Ghosn J, Raffi F, Dellamonica P, et al. Protease inhibitor resistance analysis in the MONARK trial comparing first-line lopinavir-ritonavir monotherapy to lopinavir-ritonavir plus zidovudine and lamivudine triple therapy. Antimicrob Agents Chemother. 2009;53(7):2934-2939.

30. Molto J, Santos JR, Negredo E, Miranda C, Videla S, Clotet B. Lopinavir/ritonavir monotherapy as a simplification strategy in routine clinical practice. J Antimicrob Chemother. 2007;60(2):436-439. 
31. Pulido F, Arribas JR, Delgado R, Cabrero E, Gonzalez-Garcia J, Perez-Elias MJ, et al. Lopinavir-ritonavir monotherapy versus lopinavir-ritonavir and two nucleosides for maintenance therapy of HIV. AIDS. 2008;22(2):F1-F9.

32. Delfraissy JF, Flandre P, Delaugerre C, Ghosn J, Horban A, Girard PM, et al. Lopinavir/ritonavir monotherapy or plus zidovudine and lamivudine in antiretroviral-naive HIV-infected patients. AIDS. 2008; 22(3):385-393.

33. Ghosn J, Flandre P, Cohen-Codar I, Girard PM, Chaix ML, Raffi F, et al. Long-term (96-week) follow-up of antiretroviral-naive HIV-infected patients treated with first-line lopinavir/ritonavir monotherapy in the MONARK trial. HIV Med. 2009. [Aug 13 Epub ahead of print].

34. LePrevost M, Green H, Flynn J, Head S, Clapson M, Lyall H, et al. Adherence and acceptability of once daily Lamivudine and abacavir in human immunodeficiency virus type-1 infected children. Pediatr Infect Dis J. 2006;25(6):533-537.

35. Johnson MA, Gathe JC Jr, Podzamczer D, Molina JM, Naylor CT, Chiu YL, et al. A once-daily lopinavir/ritonavir-based regimen provides noninferior antiviral activity compared with a twice-daily regimen. J Acquir Immune Defic Syndr. 2006;43(2):153-160.

36. Ananworanich J, Gayet-Ageron A, Ruxrungtham K, Chetchotisakd P, Prasithsirikul W, Kiertiburanakul S, et al. Long-term efficacy and safety of first-line therapy with once-daily saquinavir/ritonavir. Antivir Ther. 2008;13(3):375-380.

37. Eron JJ, Feinberg J, Kessler HA, Horowitz HW, Witt MD, Carpio FF, et al. Once-daily versus twice-daily lopinavir/ritonavir in antiretroviralnaive HIV-positive patients: a 48-week randomized clinical trial. J Infect Dis. 2004;189(2):265-272.

38. Macassa E, Delaugerre C, Teglas JP, Jullien V, Treluyer JM, Veber F, et al. Change to a once-daily combination including boosted atazanavir in HIV-1-infected children. Pediatr Infect Dis J. 2006;25(9):809-814.

39. Children. WGoATaMMoH-I. Guidelines for the Use of Antiretroviral Agents in Pediatric HIV Infection. February 23, 2009.

40. Welch S, Sharland M, Lyall EG, Tudor-Williams G, Niehues T, Wintergerst U, et al. PENTA 2009 guidelines for the use of antiretroviral therapy in paediatric HIV-1 infection. HIV Med. 2009;10(10):591-613.

41. Gupta RK, Gibb DM, Pillay D. Management of paediatric HIV-1 resistance. Curr Opin Infect Dis. 2009;22(3):256-263.

42. van der Lugt J, Autar RS, Ubolyam S, Garcia EF, Sankote J, Avihingsanon A, et al. Pharmacokinetics and short-term efficacy of a double-boosted protease inhibitor regimen in treatment-naive HIV-1infected adults. J Antimicrob Chemother. 2008;61(5):1145-1153.

43. Stebbing J, Scourfield A, Koh G, Taylor C, Taylor S, Wilkins E, et al. A multicentre cohort experience with double-boosted protease inhibitors. J Antimicrob Chemother. 2009;64(2):434-435.

44. Landman R, Capitant C, Descamps D, Chazallon C, Peytavin G, Katlama C, et al. Efficacy and safety of ritonavir-boosted dual protease inhibitor therapy in antiretroviral-naive HIV-1-infected patients: the 2IP ANRS 127 study. J Antimicrob Chemother. 2009;64(1):118-125.
45. Dunning J, Nelson M. Novel strategies to treat antiretroviral-naive HIVinfected patients. J Antimicrob Chemother. 2009;64(4):674-679.

46. Boyd M, Mootsikapun P, Burger D, Chuenyam T, Ubolyam S, Mahanontharit A, et al. Pharmacokinetics of reduced-dose indinavir/ ritonavir 400/100 mg twice daily in HIV-1-infected Thai patients. Antivir Ther. 2005;10(2):301-307.

47. Puthanakit T, van der Lugt J, Bunupuradah T, Ananworanich J, Gorowara M, Phasomsap C, et al. Pharmacokinetics and 48 week efficacy of low-dose lopinavir/ritonavir in HIV-infected children. J Antimicrob Chemother. 2009;64(5):1080-1086.

48. Laboratories. A. Kaletra (lopinavir/ritonavir) tablets and oral solution. Prescribing information. http://www.kaletra.com. Accessed 1 October 2009.

49. Oldfield V, Plosker GL. Lopinavir/ritonavir: a review of its use in the management of HIV infection. Drugs. 2006;66(9):1275-1299.

50. Rosso R, Di Biagio A, Dentone C, Gattinara GC, Martino AM, Vigano A, et al. Lopinavir/ritonavir exposure in treatment-naive HIV-infected children following twice or once daily administration. $J$ Antimicrob Chemother. 2006;57(6):1168-1171.

51. van der Lee M, Verweel G, de Groot R, Burger D. Pharmacokinetics of a once-daily regimen of lopinavir/ritonavir in HIV-1-infected children. Antivir Ther. 2006;11(4):439-445.

52. la Porte C, van Heeswijk R, Mitchell CD, Zhang G, Parker J, Rongkavilit C. Pharmacokinetics and tolerability of once- versus twicedaily lopinavir/ritonavir treatment in HIV-1-infected children. Antivir Ther. 2009;14(4):603-606.

53. van der Flier M, Verweel G, van der Knaap LC, van Jaarsveld P, Driessen GJ, van der Lee M, et al. Pharmacokinetics of lopinavir in HIV type-1-infected children taking the new tablet formulation once daily. Antivir Ther. 2008;13(8):1087-1090.

54. Ananworanich J, Kosalaraksa P, Hill A, Siangphoe U, Bergshoeff A, Pancharoen C, et al. Pharmacokinetics and 24-week efficacy/safety of dual boosted saquinavir/lopinavir/ritonavir in nucleoside-pre-treated children. Pediatr Infect Dis J. 2005;24(10):874-879.

55. Kosalaraksa P, Bunupuradah T, Engchanil C, Boonrak P, Intasan J, Lumbiganon $\mathrm{P}$, et al. Double boosted protease inhibitors, saquinavir, and lopinavir/ritonavir, in nucleoside pre-treated children at 48 weeks. Pediatr Infect Dis J. 2008;27(7):623-628

56. Bunupuradah T, van der Lugt J, Kosalaraksa P, Engchanil C, Boonrak P, Puthanakit T, et al. Safety and efficacy of a double-boosted protease inhibitor combination, saquinavir and lopinavir/ritonavir, in pre-treated children at 96 weeks. Antivir Ther. 2009;14(2):241-248.

57. Robbins BL, Capparelli EV, Chadwick EG, Yogev R, Serchuck L, Worrell C, et al. Pharmacokinetics of high-dose lopinavir-ritonavir with and without saquinavir or nonnucleoside reverse transcriptase inhibitors in human immunodeficiency virus-infected pediatric and adolescent patients previously treated with protease inhibitors. Antimicrob Agents Chemother. 2008;52(9):3276-3283.
HIV/AIDS - Research and Palliative Care

\section{Publish your work in this journal}

HIV/AIDS - Research and Palliative Care is an international, peerreviewed open-access journal focusing on advances in research in HIV, its clinical progression and management options including antivira treatment, palliative care and public healthcare policies to control viral spread. The journal welcomes original research, basic science,

\section{Dovepress}

clinical \& epidemiological studies, reviews \& evaluations, expert opinion \& commentary, case reports \& extended reports. The manuscript management system is completely online and includes a very quick and fair peer-review system. Visit http://www.dovepress.com/ testimonials.php to read real quotes from published authors. 